\title{
MORFOLOGIA DA WULFENITA DE ITAPIRAPUAN, São PaUlo
}

\author{
William Gerson Rolim de Camargo
}

Foi Wulfen quem primeiro descreveu, em 1785, o mineral de composição química $\mathrm{PbMoO}_{4}$, sob o nome de espato de chumbo ou chumbo espático. Von Haindinger, em honra àquele mineralogista austríaco, deu a êsse mineral, a denominação de wulfenita.

O estudo cristalográfico foi feito pela primeira vez por Haüy, em 1801, e, mais pormenorizado, por Mohs, Levy, Marignac e Reuss, posteriormente. A relação paramétrica fundamental foi calculada pela primeira vez por Dauber, em 1859, a partir de medidas feitas em cristais das minas Bleiberg e Zinnwald.

Durante muito tempo, pensou-se que a wulfenita tivesse a composição $\mathrm{PbWO})_{4}$, só se verificando ser $\mathrm{PbMoO}_{4}$, depois da determinação do peso específico por Breithaupt e a verificação de $\mathrm{MoO}_{3}$, por Klaproth.

A wulf enita constitue, geralmente, um produto de alteração. $\mathrm{E}$ ' encontrada em veios de galena, em associacão com outros minerais de alteração: cerussita, anglesita, piromorfita e fosgenita.

Considerando-se que no Brasil nada há com relação a cristalografia dêsse mineral, o autor resolveu esboçar aqui, algumas notas sòbre as principais formas encontradas e os hábitos mais freqüentes.

Mencione-se aqui, contudo, os trabalhos de D. Guimarães e Octavio Barbosa sôbre o mesmo mineral.

Em Itapirapuan, local distante cêrca de $30 \mathrm{~km}$ de Ribeira, cidade limítrofe entre os Estados de S. Paulo e Paraná, foi observada wulfenita em filóes hidrotermais de galena argentífera. $O$ materiad de estudo nos foi gentilmente cedido pelo sr. Pedro Maciel.

Os cristais, em geral, exibem faces planas, as quais permitem bòas medidas goniométricas. Outras faces, entretanto, são irregullares e acarretam nas medidas dos ângulos maiores erros experimentais.

Foram observadas 10 formas em 7 cristais medidos: 
Essas formas são as seguintes: $\{001\},\{101\},\{10 \overline{1}\},\{102\}$, $\{102\},\{111\},\{11 \overline{1}\},\{113\},\{113\}$ e $\{1,0,12\}$.

Os hábitos observados são dois, 'e mostram as seguintes combinações de formas:

$$
\begin{aligned}
& \{101\}\{10 \overline{1}\} \\
& \{102\}\{10 \overline{2}\} \\
& \{111\}\{111\} \\
& \{113\}\{11 \overline{3}\} \quad \text { (fig. 1) } \\
& \{111\}\{11 \overline{1}\} \\
& \{113\}\{11 \overline{3}\} \\
& \{1,0,12\} \quad \text { (fig. 2) }
\end{aligned}
$$

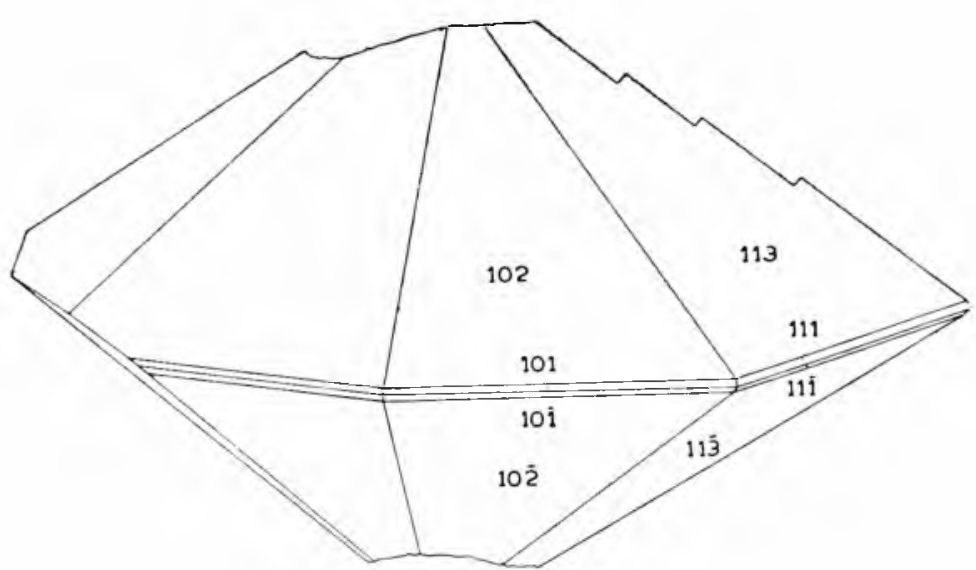

lifG. 1

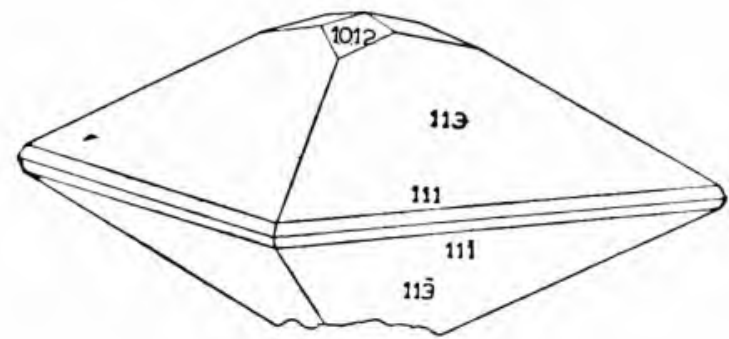

FIG. 2

Foram medidos e calculados vários ângulos diédros, para a determinação das formas acima. Ésses ângulos constam da tabela abaixo: 
Ângulos

$\begin{array}{rll}(101) & : & (102) \\ (111) & : & (111) \\ (102) & : & (10 \overline{2}) \\ (111) & : & (113) \\ (102) & : & (113) \\ (111) & : & (113) \\ (113) & : & (113) \\ (111) & : & (102) \\ (101) & : & (113) \\ (102) & : & (113) \\ (001) & : & (1,0,12) \\ (1,0,12) & : & (0,1,12) \\ (1,0,12) & : & (113)\end{array}$

I a lores

\begin{tabular}{|c|c|}
\hline Medidos & Calculados \\
\hline $19^{\circ} 15^{\prime}$ & $19^{\circ} 22^{\prime}$ \\
\hline $\begin{array}{lll}48^{\circ} & 18^{\prime}\end{array}$ & 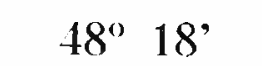 \\
\hline $103^{\circ} 33^{\prime}$ & $103^{\circ} 28^{\prime}$ \\
\hline $29^{\prime \prime} 13^{1 / 2}$ & $29^{\circ} 13^{\prime}$ \\
\hline $27^{\circ} 02^{\prime}$ & $26^{\circ} \quad 57$ \\
\hline $77^{\circ} \quad 32$ & $77^{\circ} 31^{\prime}$ \\
\hline $106^{\circ}+31 / 2$ & $166^{\circ}+11^{1 / 2}$, \\
\hline $45^{\circ} 14^{\prime}$ & $43^{\circ} 53^{\prime}$ \\
\hline $37^{\circ} 54^{1 / 2}$, & $38^{\prime \prime} 11^{\prime}$ \\
\hline $111^{\circ} 12^{1 / 2}$ & $111^{\circ} 39^{\prime}$ \\
\hline $6^{\circ} 44^{\prime}$ & $7^{\circ} 29^{\prime}$ \\
\hline $9^{\circ} 3 \overline{7}^{\prime}$ & $10^{\circ} \quad 14^{\prime}$ \\
\hline $31^{\circ} 02^{\prime}$ & $81^{\circ} 43^{\prime}$ \\
\hline
\end{tabular}

A relação paramétrica fundamental foi calculada com auxílio do ângulo (111):(111), tendo sido obtida a seguinte relação:

$$
\mathrm{a}: \mathrm{c}=1: 1,57 \mathrm{7} 1
$$

valor êste idêntico ao obtido por Dauber, e, caracteristico da wulfenita com ausência de cálcio.

() valor da relação paramétrica da wulfenita, varia com a composição quimica, principalmente com o teòr em Ca.

Abaixo podemos comparar diversas relaçós paramétricas calculadas por autores diferentes, onde poderemos vèr que aquela encontrada por nós se aproxima do valor de Dauber

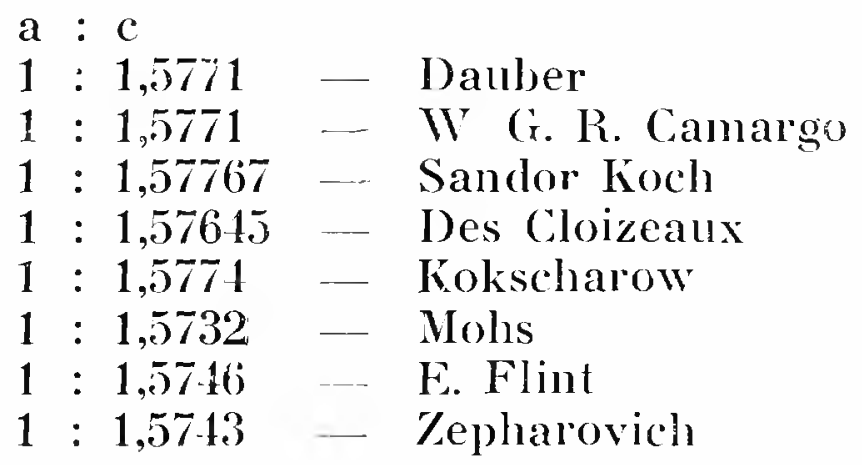

Summary

The purpose of this paper was the study of the cristallography of the mineral wulfenite. This mineral occurs in cavities com- 
monly associated with galena, anglesite, and the other characteristic minerals of the oxidized lead veins in the place named Itapirapuan, State of São Paulo, Brazil. It is believed to be of secondary origin, formed at the expense of a mineral containing molyb. denum. Crystals usually simple in habit, are commonly pyramidal. Crystals are perfect and sub translucent. Color wax yellow - to orange - yellow.

Observed forms :

$\{001\}, \quad\{101\}, \quad\{10 \overline{1}\}, \quad\{102\}, \quad\{10 \overline{2}\}, \quad\{111\}, \quad\{111\}, \quad\{113\}$,
$\{11 \overline{3}\}$ e $\{1,0,12\}$.

Axes: a : c $1: 1,5771$.

\section{Bibliografia}

Artini, E. - Alcuni minerali di Laorca e Ballabio, (1900), Miläo.

Doelter, C. e Leitmeir, H. - IV Band, 784, (1929)

Hintze, C. - I Band, 4.037, (1930).

Koch, S. - Zeits. Kr., 6, 389, (1882)

Pelloux, Alberto - Sulla wulfenite di Gennamari in Sardegna - Gabinete di Mineralogia della R. Universitá di Roma.

Rabello, C. Q. - Molibdênio no Brasil - Min. e Met., Vol. VI.

Traverso, G. B. - Sarrabus e suoi minerali, (1898), pg. 27 - Alba Itália. 